\title{
Feasibility study of crystallization process for water softening in a pellet reactor
}

\author{
${ }^{1 *}$ A. H. Mahvi, ${ }^{2}$ F. Shafiee and ${ }^{1}$ K. Naddafi \\ ${ }^{1}$ Department of Environmental Health Engineering, School of Public Health, Center for Environmental Research, Tehran \\ University of Medical Sciences, Tehran, Iran \\ ${ }^{2}$ Department of Environmental Health, Shahrood University of Medical Sciences, Shahrood, Iran
}

\begin{abstract}
One of the undesirable characteristics of some groundwater sources is hardness, which has some adverse effects on water pipes, boilers and soap consumption. Therefore several treatment processes have been introduced to remove or reduce the hardness from hard waters. One of the new innovations in this regard is crystallization process. Hardness can be removed from hard waters by growth of calcium carbonate crystals in a fluidized bed reactor called pellet reactor. The design, setting up, starts up and reaching optimal condition for calcium carbonate crystallization process in a pellet reactor which has been initially seeded with sand as a crystal citation can be a successful solution for treatment of hard waters. The chemistry of pellet softening process is essentially the same as conventional softening process, instead of precipitation of calcium carbonate which does not have any useful consumption and must be removed once in a while some how, crystallization process in a fluidized bed reactor produces pure solid grain of calcite. These pellets can be used in some industries and are in fact an economic commodity. For this purpose a pilot was set up as a crystallization reactor and water with total hardness ranging from 150 up to $500 \mathrm{mg} / \mathrm{l}$ as $\mathrm{CaCO}_{3}$ was fed to the system with a flow rate of $24 \mathrm{l} / \mathrm{hr}$. To remove hardness, caustic and soda, lime milk was fed to the system separately at first stage at then together. The formation of $\mathrm{CaCO}_{3}$ crystals on the surface of sands represented the reduction of hardness. An analysis is made for the characteristics of a softed water resulted from the use of caustic soda, lime milk or both as regent.
\end{abstract}

Key words: Hardness, pellet reactor, softening, calcium carbonate, crystallization

*Correponding Author,E.mail :ahmahvi@yahoo.com

\section{Introduction}

Hardness which is one of the chemical characteristics of water is a cation concentration of some metals in the solution. When the solution is super saturated, the cations in the water can precipitate as a hard scale. Carbonate hardness is sensitive to temperature and can precipitate easily. Also at high temperatures $\mathrm{Mg}$ salts can produce hard scales in the boilers (World Health Organization and United Nations Environment Program, 1996).

$$
\begin{gathered}
\mathrm{Ca}\left(\mathrm{HCO}_{3}\right)_{2} \stackrel{\text { Heat }}{\longrightarrow} \mathrm{CaCO}_{3} \downarrow+\mathrm{CO}_{2}+\mathrm{H}_{2} \mathrm{O} \\
\mathrm{Mg}\left(\mathrm{HCO}_{3}\right)_{2}-\stackrel{\text { Heat }}{\longrightarrow} \mathrm{Mg}(\mathrm{OH})_{2} \downarrow+2 \mathrm{CO}_{2}
\end{gathered}
$$

Calcium and Magnesium are found in natural groundwaters most often (Torkian, 1995) where the concentration of $\mathrm{Ca}$ is about 2 times as $\mathrm{Mg}$. In water this amount is 5 times as much (Chalkesh Amiri, 1997). In addition, Fe and Mn also contribute to hardness, there are several physical and chemical processes to remove or reduce the water hardness, such as ion exchange, lime softening, reverse osmosis, electrodialysis and so on. Any of these processes do have some advantages and disadvantages.

One of the innovations in treatment of hard waters is application of Pellet Reactor (PR). Which contrast to conventional softening processes, produces no sludge (Benefild Larry, et al., 1982). In this process very tiny spherical crystal beads are produced with calcite nature (Rankin and Sutcliffe, 1999). With the use of sands and grains as seeds the removal efficiency of hardness can be increased (Todd, et al., 1994). In pellet reactors there is a chance to remove other cations such as $\mathrm{Sr}$, Fe and $\mathrm{Mn}$ as well as calcium and manganesium (Todd, et al., 1994). It is also possible to reduce sulfate concentration of over $600 \mathrm{mg} / \mathrm{l}$ to lower than $70 \mathrm{mg} / \mathrm{l}$. with the addition of calcium aluminates and lime, in such a condition $\mathrm{Ca}$, and $\mathrm{Mg}$ have been removed almost completely. When lime is used, there is a 
need for filters following pellet reactors but if caustic soda is used, the loading on filter will be much lower (Wilms and Dilk, 1992). Equal nucleation will lead to production of micro crystals which can be seen. These tiny micro crystals are smaller than 0.05 $\mu \mathrm{m}$. in size and therefore they can not be removed by rapid sand filters after pellet reactors. These microcrystal doses not have adverse effect on drinking water quality and on the other hand can act as a new citation for calcium carbonate crystallization especially in hot waters (Wilms, et al., 1991). Aeration of ground waters before entering pellet reactor and stripping carbon dioxide from waters can lead to higher efficiency of the reactor and reduction of lime consumption. The $\mathrm{pH}$ of finished water from pellet reactor should be reduced by sulfuric acid addition (Centralized Softening, 1999). The commercial pellet reactors are $6-12 \mathrm{~m}$. high and 0.5 to $4 \mathrm{~m}$ in diameters. The sand size is in the range of 0.2$0.3 \mathrm{~mm}$. The crystallized sand can grow as big as 1$2 \mathrm{~mm}$. in size.The advantages of pellet reactor softening over conventional process are:

- Small in size with respect to the process.

- Lower reaction time up to 16 times as much.

- Clean waste production.

- Easy handling of crystal grains.

- The possibility for consumption of crystals in industries (Howes and Moulds, 1999).

The objective of this research was to treat hard waters and reducing the total hardness down to desirable water for potable or industrial use. Since, the purpose of this research was to study the feasibility of the calcium carbonate crystal formation on the proper situation, a pilot plant pellet reactor was set up to do so. This study has been done for the first time in Iran on 2000.

\section{Materials and Methods}

A Plexiglas reactor with a submerged media and up-flow stream was selected, the characteristics of pilot included:

Diameter: 1.9 cm., height: $175 \mathrm{~cm}$., volume: 0.5 l. For uniform distribution of water in the reactor a perforated platter was used under the cylinder.

Effluent of this reactor after $\mathrm{pH}$ adjustment was directed for filtration. The characteristics of the filter unit were:

Diameter: $25 \mathrm{~cm}$., height: $200 \mathrm{~cm}$., volume: $95 \mathrm{l}$. PR reactor or crystal actor is a cylindrical shape reactor that is packed with suitable material such as sand, quartz or mineral material with suitable diameter. Figure 1 represents the flow diagram for this process. The reactor was filled up to $0.6 \mathrm{~m}$. in height by sand with diameter ranging $0.2-0.3 \mathrm{~mm}$. and adjusting surface overflow rate was adjusted in the range of 24, 19.8 and $16.22 \mathrm{l} / \mathrm{hr}$.Calcium carbonate was produced around the sand particle as primary nucleus. Influent hard water flow to the pilot plant and chemicals addition for softening process were from the bottom of the reactor. The reactor was up-flow system. Raw water with total hardness of 150,300 and $500 \mathrm{mg} / \mathrm{l}$ as calcium carbonate was prepared. The pilot run was designated for 3 different phases: addition of $\mathrm{Ca}(\mathrm{OH})_{2}$, addition of $\mathrm{NaOH}$ and addition of both. The surface overflow rate of water was sufficient for submerging the pellet media and can producing a high specific surface area for increasing synthetic reaction.

Softening reaction was done in submerged media with subsequent increase in the pellet particle size then, they accumulated in the end of submerged media for discharg and replace with new media. Metallic ions can be crystallized on crystalline nucleus. In this situation, water effluent had no metallic ions and pellet impurities such as organic suspended matter and other ions so there was not any accumulation on the pellet reactor.

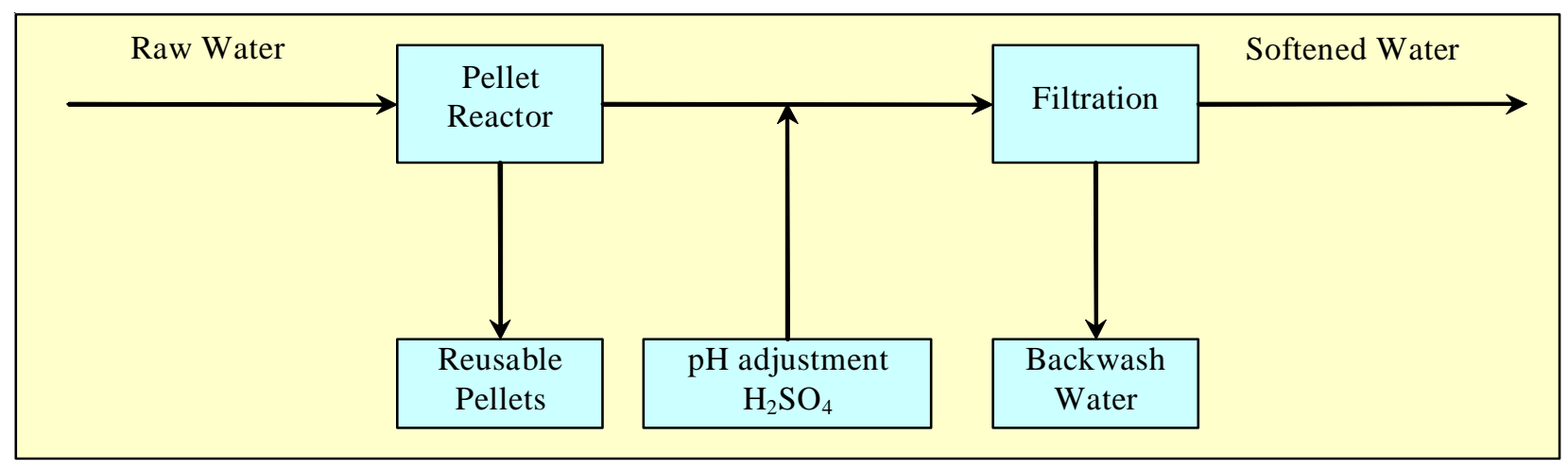

Figure 1: Pellet Reactor flow diagram 
The chemical reactions to take place for hardness removal are as below:

$$
\begin{aligned}
& \mathrm{Ca}\left(\mathrm{HCO}_{3}\right)_{2}+\mathrm{Ca}(\mathrm{OH})_{2} \rightarrow 2 \mathrm{CaCO}_{3} \downarrow+2 \mathrm{H}_{2} \mathrm{O} \\
& \mathrm{Ca}\left(\mathrm{HCO}_{3}\right)_{2}+2 \mathrm{NaOH} \rightarrow \mathrm{CaCO}_{3} \downarrow+\mathrm{Na}_{2} \mathrm{CO}_{3}+ \\
& 2 \mathrm{H}_{2} \mathrm{O} \\
& 2 \mathrm{Ca}\left(\mathrm{HCO}_{3}\right)_{2}+\mathrm{Ca}(\mathrm{OH})_{2}+2 \mathrm{NaOH} \rightarrow 3 \mathrm{CaCO}_{3} \downarrow+ \\
& \mathrm{Na}_{2} \mathrm{CO}_{3}+4 \mathrm{H}_{2} \mathrm{O}
\end{aligned}
$$

Therefore, the chemicals that were consumed were $\mathrm{NaOH}$ and $\mathrm{Ca}(\mathrm{OH})_{2}$ which were added eights separately or simultaneously. Figure 2 represents the schematic of the pilot.

\section{Results}

Figure 3 represents the effect of chemical addition on total hardness removal by the pellet reactor. The raw water had a concentration of $150 \mathrm{mg} / \mathrm{l}$ as $\mathrm{CaCO}_{3}$. For each step, addition of individual chemicals as $\mathrm{NaOH}, \mathrm{Ca}(\mathrm{OH})_{2}$ and both of them are shown. Figure 4 is the result of hard water fed to the pellet reactor with concentration of $300 \mathrm{mg} / \mathrm{l}$ as $\mathrm{CaCO}_{3} \mathrm{~A}$ gain in each step, lime milk, caustic soda and both of these chemicals were added to the fed water for hardness removal.
Figure 5 represents the hardness removal from fed water with concentration of $500 \mathrm{mg} /$ as $\mathrm{CaCO}_{3}$ by. Lime milk, caustic soda and both of these chemicals were added to the fed water for hardness removal. In all these stages, hardness of water was successfully reduced to acceptable levels. The formation of white calcium carbonate crystals on the surface of the brown sands confirms the removal of hardness. Figure 6 shows the brown initial sands before crystal formation and white sands after that.

\section{Discussion and Conclusion}

The result on the removal of hardness with influent concentration of 150,300 and $500 \mathrm{mg} / \mathrm{l}$ as $\mathrm{CaCO}_{3}$ is about $50 \%$. These results showed that the ability of pellet reactor for hardness removal is independent of hardness concentration.

Since the total surface area for crystal formation is the same, therefore the efficiency is almost equal. For any of the influent concentration of hardness and a flowrate of 24, $1 / \mathrm{hr}$ the efficiency was around $50 \%$.The result of hardness removal for influent concentration $300 \mathrm{mg} / \mathrm{l}$ as $\mathrm{CaCO}_{3}$ with addition of $\mathrm{Ca}(\mathrm{OH})_{2}$ and $\mathrm{NaOH}$ were 20 and $52 \%$ respectively. These figures for influent concentration of $150 \mathrm{~m} / \mathrm{gl}$ as $\mathrm{CaCO}_{3}$ were 57 and $67 \%$ respectively. These results showed that $\mathrm{NaOH}$ addition has more effect on hardness removal.

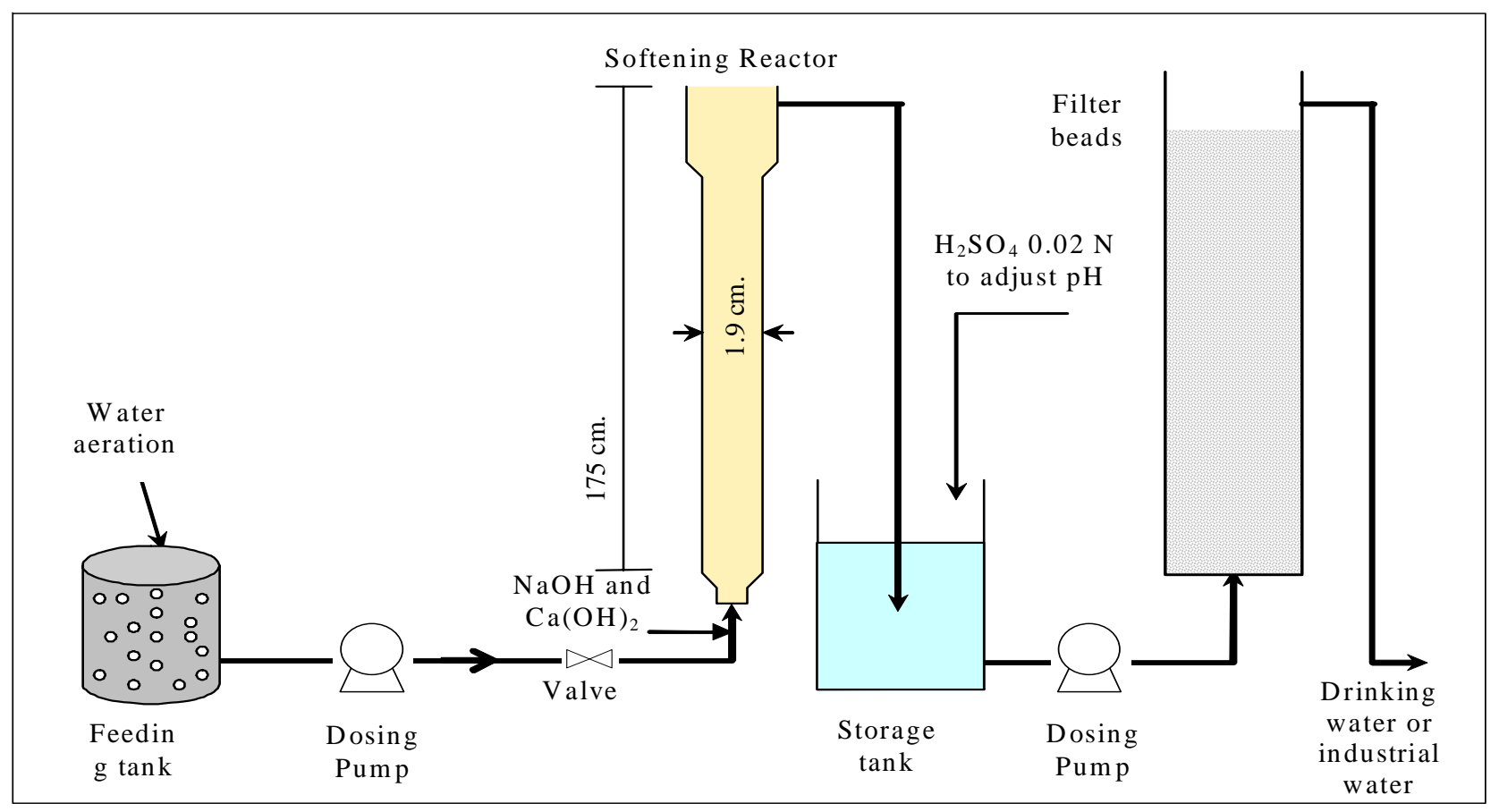

Figure 2: Water softening technology in PR 


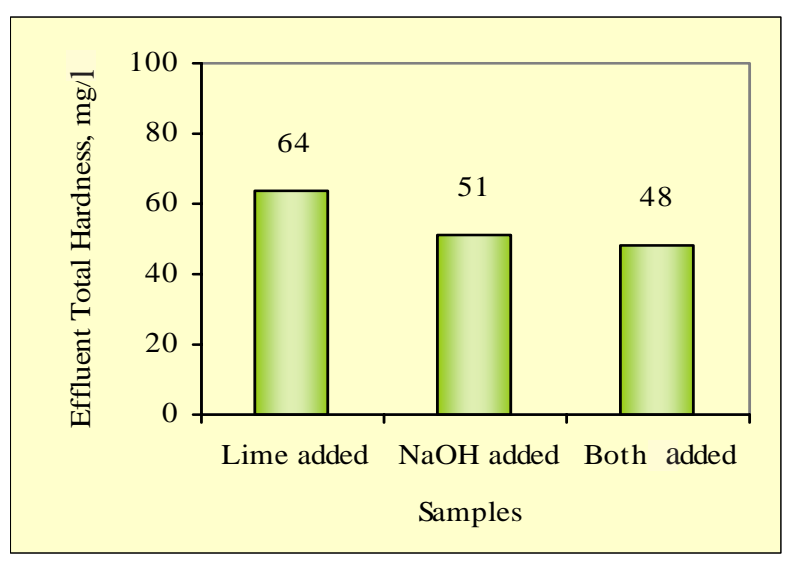

Figure 3: Effect of chemical addition on total hardness removal

(Inf. total hardness $=150 \mathrm{mg} / \mathrm{l} \mathrm{CaCO}_{3}, \mathrm{Q}=24 \mathrm{l} / \mathrm{hr}$.)

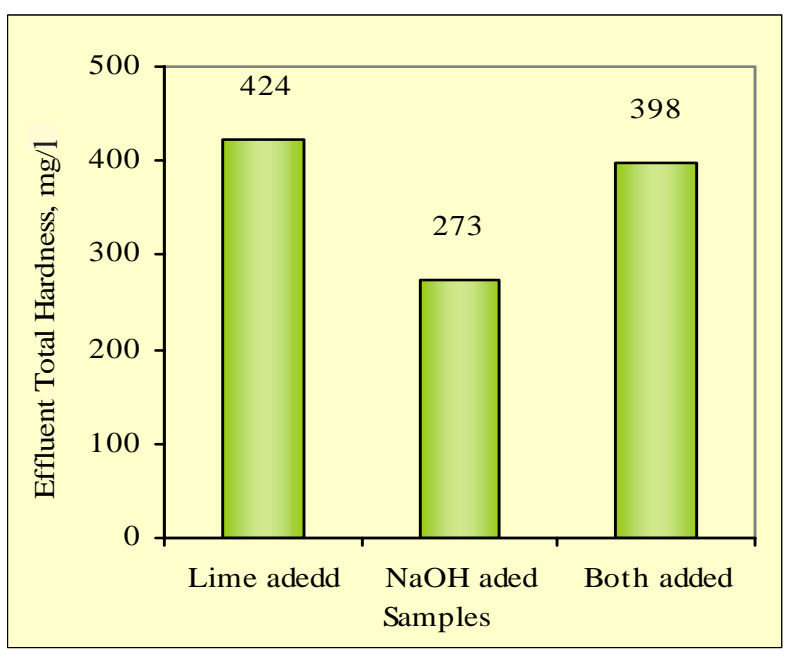

Figure 5: Effect of chemical addition on total hardness removal

(Inf. total hardness $=500 \mathrm{mg} / \mathrm{l} \mathrm{CaCO}_{3}, \mathrm{Q}=24 \mathrm{l} / \mathrm{hr}$.)

Unfortunately the addition of both $\mathrm{Ca}(\mathrm{OH})_{2}$ and $\mathrm{NaOH}$ have no significant difference with compare to $\mathrm{Ca}(\mathrm{OH})_{2}$ or $\mathrm{NaOH}$ added separately. This is due to absence of high permanent hardness in the solution. The mass balance for sand at the end of the study was about $37 \mathrm{mg}$. This increase in sand mass is as a result of crystal formation on the surface of the sand. It should be mentioned that the mass balance in that particular phase for calcium carbonate removal almost confirms the precipitation mass balance. The operation of the system confirms that these kinds of Pellet softening reactor can be used for potable and industrial water treatment. Fortunately there were no sludge in the pilot and the hardness can be disposed safely to the environment or be used where they are needed.

The study was in accordance with another similar study for hardness removal from hard waters. In that research some $50 \%$ of the calcium carbonate

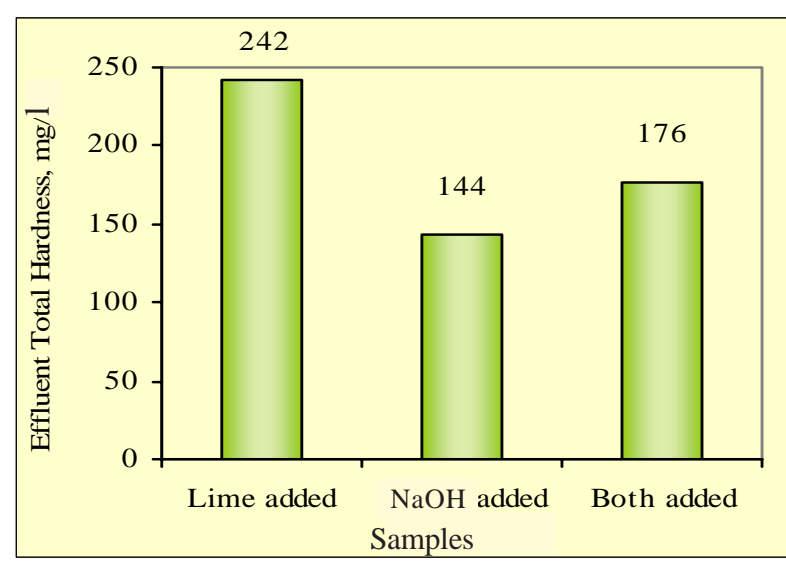

Figure 4: Effect of chemical addition on total hardness removal

(Inf. total hardness $=300 \mathrm{mg} / \mathrm{CaCO}_{3}, \mathrm{Q}=24 \mathrm{l} / \mathrm{hr}$.)

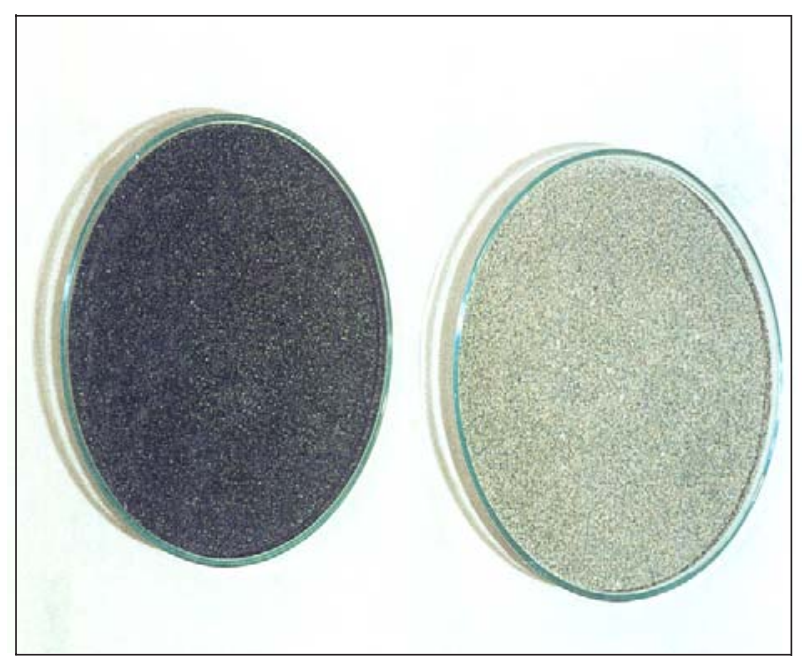

Figure 6: Sands before and after crystallization

was reduced by pellet reactor (Todd, et al., 1994). In another study using crystallization reactor for hardness removal, the addition of lime milk and caustic soda was experienced and it had similar results as this paper (Wiliams and Dilk, 1992; Rankin and Sutcliffe, 1999).

In a large scale hard water treatment by crystallization pellet reactor, crystal grains similar to this research were produced.

\section{References}

Benefild Larry, D., J. R. Judkins, F. Joseph and L. Barron Weand, Process chemistry for water and wastewater

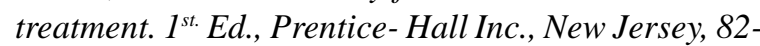
355, 1982

Centralized Softening, Centralized softening in the lower Rhine basi. Water 21, IWA Publishing JulyAugust: 19-24, 1999 
Chalkesh Amiri, M., Water treatment principals. Isfahan, Arkan Publication, 1: 2-205, 1997

Howes, D. and B. Moulds, Pellet softening for salinity and hardness reduction at Neerabup. Western Australia, Water Supply, 17: 7-13, 1999

Rankin, A. H. and P. J. C. Sutcliffe, Morphology, chemistry and growth mechanisms of calcite concretions from an industrial water-softening process: Implication for the origin of natural ooids is sediments. Proceeding of the of the geologists association, 110 (1): 33-40, 1999

Todd I. A., D. Verdoes, L. Sijstermans, J. V. D. Meer and J. $M$. Hanemaaijer, The removal of strontium and calcium from aqueous Streams. Canadian Institute of Mining, Metallurgy and Petroleum, 43: 181-195, 1994
Torkian, A., Environmental Health, $1^{\text {st. }}$ Ed. Isfahan Kankash Publication, 1: 14-148, 1995

Wilms, D. A. and V. J. C. Dilk, European practice in drinking water softening by crystallization in a pellet reactor, Water Treatment, 7: 269-280 , 1992

Wilms, D. A., C. P. Dotermont, J. De Moel and D. Blois, Turbidity and scaling of drinking water after softening with pellet reactors. $\mathrm{H}_{2} \mathrm{O}, 24:$ 72-78, 1991

World Health Organization and United Nations Environment Program. Water Quality Monitoring.

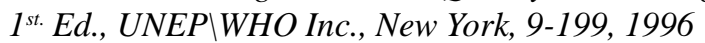

